\title{
Biology and pathophysiology of the amyloid precursor protein
}

\author{
Hui Zheng ${ }^{1 *}$ and Edward $\mathrm{H} \mathrm{KoO}^{2}$
}

\begin{abstract}
The amyloid precursor protein (APP) plays a central role in the pathophysiology of Alzheimer's disease in large part due to the sequential proteolytic cleavages that result in the generation of $\beta$-amyloid peptides (A $\beta$ ). Not

surprisingly, the biological properties of APP have also been the subject of great interest and intense investigations. Since our 2006 review, the body of literature on APP continues to expand, thereby offering further insights into the biochemical, cellular and functional properties of this interesting molecule. Sophisticated mouse models have been created to allow in vivo examination of cell type-specific functions of APP together with the many functional domains. This review provides an overview and update on our current understanding of the pathobiology of APP.
\end{abstract}

\section{Introduction}

Alzheimer's disease (AD) is the most common cause of dementia and neurodegenerative disorder in the elderly. It is characterized by two pathological hallmarks: senile plaques and neurofibrillary tangles, as well as loss of neurons and synapses in selected areas of the brain. Senile plaques are extracellular deposits composed primarily of amyloid $\beta$-protein $(A \beta)$, which is a 40-42 amino acid long peptide derived by proteolytic cleavages of the amyloid precursor protein (APP), with surrounding neuritic alterations and reactive glial cells. $A \beta$ has taken a central role in Alzheimer's disease research for the past two decades in large part because of the amyloid cascade hypothesis which posits that $A \beta$ is the common initiating factor in AD pathogenesis. Because of this, the processing of APP and generation of A $\beta$ from APP have been areas of substantial research focus by a large number of laboratories. By comparison, whether full-length APP or other non-A $\beta$ APP processing products play a significant role in $\mathrm{AD}$ or contribute to other neurological disorders has received somewhat less consideration. For example, it is unclear if the mutations in the APP gene found in the hereditary form of familial AD and the related hereditary amyloid angiopathy with cerebral hemorrhage (http:// www.molgen.ua.ac.be/ADMutations/) are pathogenic solely because of perturbed $A \beta$ properties. However,

\footnotetext{
* Correspondence: huiz@bcm.edu

${ }^{1}$ Huffington Center on Aging and Department of Molecular \& Human

Genetics, Baylor College of Medicine, Houston, TX 77030, USA

Full list of author information is available at the end of the article
}

increasing evidence supports a role of APP in various aspects of nervous system function and, in view of the recent negative outcome of clinical trials targeting $A \beta$ production or clearance, there is renewed interest in investigating the physiological roles of APP in the central nervous system (CNS) and whether perturbation of these activities can contribute to $\mathrm{AD}$ pathogenesis.

This review will update some of the recent findings on the physiological properties of APP. We start with a general overview of APP. Because APP consists of multiple structural and function domains, we will focus our review by addressing the properties of the full-length APP as well as APP extracellular and intracellular domains. Finally, we provide an update on the current knowledge concerning the APP function in vivo, especially recent findings from the APP conditional knockout mice and knock-in alleles expressing various APP domains. For discussions on the pathophysiology of $A \beta$, there are many excellent reviews that summarize this area in detail but is otherwise beyond the scope of this article.

\section{A. APP Overview \\ a) The APP Family}

APP is a member of a family of conserved type I membrane proteins. The APP orthologs have been identified in, among others, C. elegans [1], Drosophila [2,3], Zebrafish [4] and Xenopus Laevis [5,6]. Three APP homologs, namely $A P P[7,8]$, APP like protein 1 (APLP1) [9] and 2 (APLP2) $[10,11]$, have been identified in mammals (Figure 1). These proteins share a conserved structure 


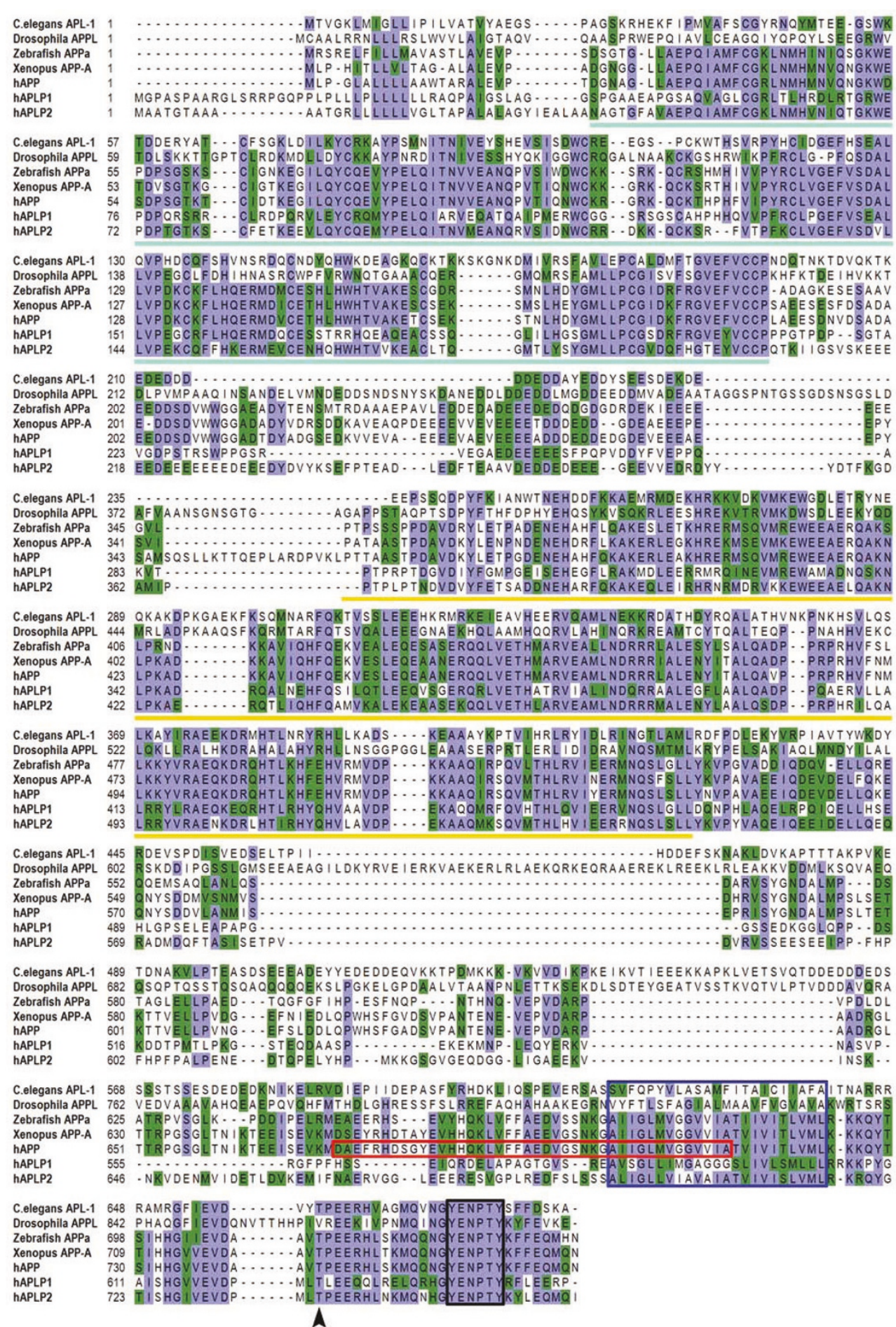

Figure 1 Comparison of protein sequences of C. elegans APL-1, Drosophila APPL, Zebrafish APPa, Xenopus APP-A and the human APP, APLP1 and APLP2. Purple sequences indicate identical homology while green references similar amino acids. Homologous regions include the E1 domain (light blue line), E2 domain (yellow line) and sequences within the C-terminus such as the conserved Thr site (arrow head) and YENPTY motif (black box). The transmembrane domain and A $\beta$ sequence are noted by the blue and red boxes respectively. 
with a large extracellular domain and a short cytoplasmic domain. There are several conserved motifs, including the E1 and E2 domains in the extracellular region and the intracellular domain, the latter exhibiting the highest sequence identity between APP, APLP1 and APLP2. Of interest, the $A \beta$ sequence is not conserved and is unique to APP. Additionally, the APP and APLP2 genes, but not APLP1, were identified in Xenopus Laevis, suggesting that the first gene duplication resulted in $A P P$ and preAPLP in the evolution of the APP superfamily, prior to the separation of mammals and amphibians [12]. Thus, APLP1 diverged from the APLP2 gene such that APLP1 does not contain two additional exons present in both $A P P$ and $A P L P 2$, one of which encodes a Kunitz-type protease inhibitor domain. With this history, it is not surprising that APLP1 is found only in mammals and, unlike $A P P$ and $A P L P 2$, it is expressed only in brain. However, given the sequence identity between the three genes, it is also not unexpected that the mammalian APP homologs play redundant activities in vivo (discussed in "The in vivo Function of APP"). The functional conservation of APP across species is also documented by the partial rescue of the Drosophila Appl null behavioral phenotype by human APP [3]. These observations indicate that the conserved motifs, rather than the non-conserved $A \beta$ sequence, likely underline the physiological functions among the APP species.

\section{b) APP Expression}

The mammalian APP family of proteins is abundantly expressed in the brain. Similar to Drosophila Appl [13], APLP1 expression is restricted to neurons. However, although highly enriched in the brain, APP and APLP2 are ubiquitously expressed outside of the brain. The human APP gene, located on the long arm of chromosome 21 , contains at least 18 exons $[14,15]$. Alternative splicing generates APP mRNAs encoding several isoforms that range from 365 to 770 amino acid residues. The major $A \beta$ peptide encoding proteins are 695,751 , and 770 amino acids (referred to as APP695, APP751 and APP770). APP751 and APP770 contain a domain homologous to the Kunitz-type serine protease inhibitors (KPI) in the extracellular sequences, and these isoforms are expressed in most tissues examined. The APP695 isoform lacks the KPI domain and is predominately or even exclusively expressed in neurons and accounts for the primary source of APP in brain [16]. For example, there is a burst of increased expression of APP695 during neuronal differentiation. However, following brain injury, expression of the APP751/770 isoforms is substantially increased in astrocytes and microglial cells $[17,18]$. The reason and functional significance for this apparent tissue-specific alternative splicing is poorly understood.

\section{c) APP Processing}

APP is processed in the constitutive secretory pathway and is post-translationally modified by $\mathrm{N}$ - and O-glycosylation, phosphorylation and tyrosine sulfation (reviewed in [19]). Full-length APP is sequentially processed by at least three proteases termed $\alpha$-, $\beta$ - and $\gamma$-secretases (Figure 2). Cleavage by $\alpha$-secretase or $\beta$-secretase within the luminal/ extracellular domain results in the shedding of nearly the entire ectodomain to yield large soluble APP derivatives (called APPs $\alpha$ and APPs $\beta$, respectively) and generation of membrane-tethered $\alpha$ - or $\beta$-carboxyl-terminal fragments (APP-CTF $\alpha$ and APP-CTF $\beta$ ). The APP-CTFs are subsequently cleaved by $\gamma$-secretase to generate either a $3 \mathrm{kDa}$ product (p3, from APP-CTF $\alpha$ ) or A $\beta$ (from APP-CTF $\beta$ ), and the APP intracellular domain (AICD).

The major neuronal $\beta$-secretase is a transmembrane aspartyl protease, termed BACE1 ( $\beta$-site APP cleaving enzyme; also called Asp-2 and memapsin-2) [20-24], and cleavage by BACE1 generates the $\mathrm{N}$-terminus of $A \beta$. There is an alternative BACE ( $\left.\beta^{\prime}\right)$ cleavage site following Glu at position +11 of the $A \beta$ peptide [25]. In addition, there is a BACE2 homolog which is expressed widely but does not appear to play a role in $A \beta$ generation as it appears to cleave near the $\alpha$-secretase site $[26,27]$. Of note, cathepsin B has also been proposed to act as a $\beta$-secretase $[28,29]$, but whether generation of $A \beta$ in brain requires the coordinated action of both BACE1 and cathepsin B is not known but unlikely given the near total loss of $A \beta$ in BACE1 deficient mice $[23,24,30]$.

While cleavage at the $\beta$-site is specific to BACE1 and possibly cathepsin $B$, it was initially believed that a number of proteases, specifically members of the ADAM (a disintegrin and metalloprotease) family of proteases including ADAM9, ADAM10 and ADAM17

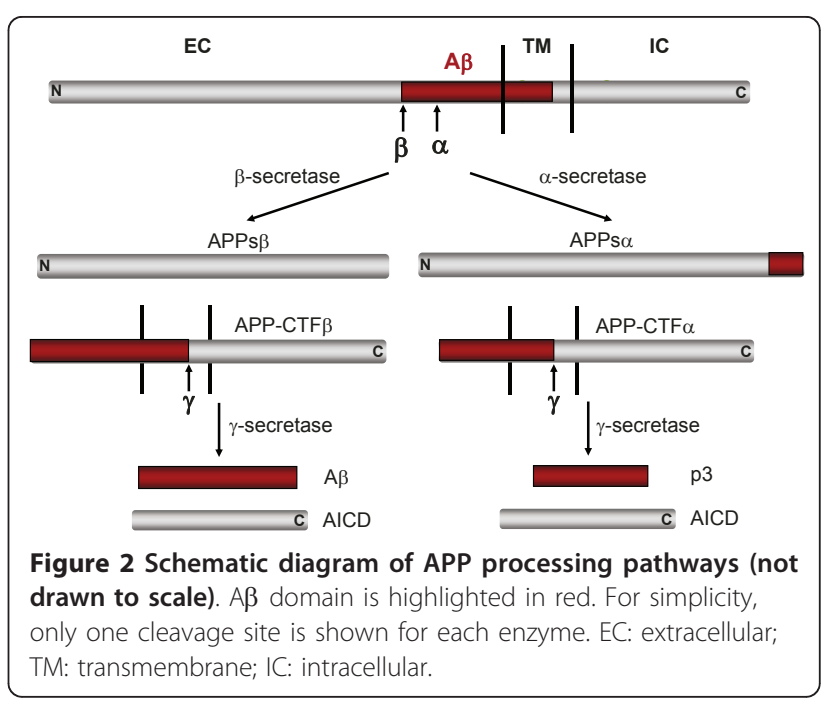


are candidates for the $\alpha$-secretase (reviewed in [31]). It was reported that APP $\alpha$-secretase cleavage can be stimulated by a number of molecules, such as phorbol ester or via protein kinase $\mathrm{C}$ activation, in which case, this so-called regulated cleavage is mediated by ADAM 17 , also called TACE (tumor necrosis factor $\alpha$-converting enzyme) $[32,33]$. However, recent studies indicated that constitutive $\alpha$-secretase activity is likely to be mediated by ADAM10 [34]. Interestingly, ADAM10 is transcriptionally regulated by sirtuins [35], thus providing a mechanism where augmentation of $\alpha$-secretase activity competes for $\beta$-secretase cleavage to lower generation of full length $A \beta$ peptide. However, it should be noted that cleavage of APP by $\alpha$-secretase processing only precludes the formation of an intact full length $A \beta$ peptide. Although this latter event is commonly called the non-amyloidogenic pathway, it is unfortunately a bit of a misnomer because truncated $A \beta$ (p3 peptide) from 17-42 is also deposited in brains of AD and Down Syndrome patients [36-38], indicating that shorter $A \beta$ peptides starting at the $\alpha$-secretase site may contribute to some aspects of AD-associated amyloid pathology $[39,40]$.

As regards to $\gamma$-secretase cleavage that releases $A \beta$ from the membrane, this activity is executed by a high molecular weight complex consisting of presenilin (PS), nicastrin, anterior pharynx defective (APH1) and presenilin enhancer (PEN2) (reviewed in $[41,42]$ ). Although these four proteins form the mature $\gamma$-secretase complex, it appears that the core $\gamma$-secretase activity resides within presenilin itself functioning as an aspartyl protease $[43,44]$. In addition to generating $A \beta$ peptides of different lengths, $\gamma$-secretase appears to cleave APP in multiple sequential steps [45-47]. An initial cleavage, termed $\varepsilon$-cleavage, taking place 3-4 residues from the cytoplasmic membrane face begins this process $[48,49]$. Elegant studies by Ihara and colleagues [50-53] have led to a model whereby sequential cleavages taking place every three residues along the $\alpha$-helical face of the transmembrane domain of APP shortens the C-terminus to ultimately result in the release of $A \beta$.

It is worth mentioning that none of the secretases have unique substrate specificity towards APP. Besides APP, several transmembrane proteins such as growth factors, cytokines and cell surface receptors and their ligands, undergo ectodomain shedding by enzymes with $\alpha$-secretase activity (see [54] for an overview). The relatively low affinity of BACE1 toward APP led to the suggestion that APP is not its sole physiological substrate. Indeed, neuregulin-1 (NRG1) now appears to be a bona fide substrate of BACE1 such that the shedding of NRG1 initiated by BACE1 cleavage would direct Schwann cells to myelinate peripheral nerves during development $[55,56]$. Similarly, $\gamma$-secretase has been reported to cleave more than 50 type I membrane proteins in addition to APP (reviewed by [57]), an event that requires an initial ectodomain shedding event, usually by $\alpha$-secretase-mediated cleavage. While this cleavage in some cases has been demonstrated to initiate intracellular cell signaling, as exemplified by the $\gamma$-secretase dependent Notch activation, whether this also applies to APP and other $\gamma$-secretase substrates remains unconfirmed (see below and discussed in [58]).

\section{B. The Full-length APP a) Cell Surface Receptor}

Ever since the cloning of APP cDNA, APP has been proposed to function as a cell surface receptor. Further, the analogy between the secondary structures and proteolytic processing profiles between the Notch receptor and APP also suggests that APP could function as a cell surface receptor similar to Notch (reviewed in [59]). In support of this hypothesis, Yankner and colleagues reported that $A \beta$ could bind to APP and thus could be a candidate ligand for APP [60], a finding that has been replicated by others [61]. Another piece of evidence came from Ho and Sudhof (2004) who showed that the APP extracellular domain binds to F-spondin, a neuronally secreted glycoprotein, and this interaction regulates $A \beta$ production and downstream signaling [62]. Similarly, the Nogo-66 receptor has been shown to interact with the APP ectodomain and by which means affect $A \beta$ production [63]. Another interacting protein recently reported is Netrin-1, a soluble molecule with multiple properties including axonal guidance through chemoattraction and tumorigenesis [64]. In this instance, addition of netrin-1 to neuronal cultures led to reduction in A $\beta$ levels but also increased APP-Fe65 complex formation, thus suggesting a role in cell signaling (see below). Recently, work from the D'Adamio group showed that BRI2 could function as a putative ligand or co-receptor for APP and modulates APP processing $[65,66]$. Finally, the fact that the extracellular domains of the APP family of protein could potentially interact in trans (discussed below) suggest that APP molecules can interact in a homophilic or heterophilic manner between two cells. Overall, although a number of APP interacting proteins have been identified, it is unclear whether any of the candidates are bona fide ligands and definitive evidence supporting a physiological role of APP to function as a cell surface receptor is still lacking.

\section{b) Cell and Synaptic Adhesion}

The E1 and E2 regions in the extracellular domain of APP have been shown to interact with extracellular matrix proteins and heparin sulfate proteoglycans (reviewed in [67]), supporting its role in cell-substratum adhesion. The same sequences have also been implicated in cell-cell interactions. Specifically, X-ray analysis 
revealed that the E2 domain of APP could form parallel or antiparallel dimers [68], the latter structure would imply that there is a potential to function in transcellular adhesion. Indeed, cell culture studies support the homo- or hetero-dimer formation of the APP family members, and trans-dimerization was shown to promote cell-cell adhesion [69]. It was further shown that heparin binding to the E1 or E2 region would induce the formation of APP dimerization [70]. Besides the E1 and E2 regions, recent studies suggest that homodimerization can be promoted by the GxxxG motif near the luminal face of the membrane [71,72]. Interestingly, mutagenesis of the glycine residues in this motif resulted in production of truncated $A \beta$ peptides of 34,35 , and 38 amino acids in length [71]. On the other hand, it is unclear whether these changes in $A \beta$ generation are strictly related to APP dimerization because forced dimerization of APP with a bifunctional cross-linking agent did not lead to the same changes in $A \beta$ profile [73]. In addition, while trans-dimerization would be expected to play a role in cell-cell interactions or adhesion, it is less clear what the cellular consequences of cis-homodimerization of APP are, aside from the alterations in A $\beta$ peptides noted earlier. One possible role of dimerization is through downstream activity of the AICD peptide that is released after $\varepsilon$-cleavage, but support for this idea remains controversial. Interestingly though, using various reporter constructs, the subcellular localization of dimerized APP and APLP2 was reported to be different to that of APLP1 [74], suggesting that there are subtle functional roles in homo- or heterodimerization of the APP gene family that remain to be elucidated. Lastly, near the beginning of the $A \beta$ sequence (and near the C-terminus of APPs) is a "RHDS" tetra-peptide motif that also appears to promote cell adhesion. It is believed that this region acts in an integrin-like manner by its homology to the "RGD" sequence [75]. In this regard, it is interesting that APP colocalizes with integrins on the surface of axons and at sites of adhesion [76,77]. In support of these earlier observations, it was recently shown that APP and integrin- $\beta 1$ do interact [78] and that siRNA mediated silencing of APP during development led to defects in neuronal migration that may be related to cell adhesion [79], potentially to extracellular matrix proteins, with or without participation by integrins.

More compelling evidence of trans-APP dimerization was recently obtained in a primary neuron/HEK293 mixed culture assay. In this culture system, it was reported that trans-cellular APP/APP interaction induces presynaptic specializations in co-cultured neurons [80]. These studies identified APP proteins as a novel class of synaptic adhesion molecules (SAM) with shared biochemical properties as neurexins (NX)/neuroligins (NL), SynCAMs, and leucine-rich repeat transmembrane neuronal proteins (LRRTM) [81-86]. Like NX/NL and SynCAM-mediated synaptic adhesion in which extracellular sequences engage in trans-synaptic interactions and the intracellular domains recruit pre- or postsynaptic complexes (reviewed in [87]), both the extracellular and intracellular domains of APP are required to mediate the synaptogenic activity. Interestingly, using an affinity tagged APP molecule expressed in transgenic mice, the identified "APP-interactome" consisted of many proteins, such as Bassoon and neurexin, that are synaptic in localization [88]. Whether APP trans-synaptic interaction is involved in the recruitment of these synaptic molecules and whether APP coordinates with other synaptic adhesion complexes such as neurexin are interesting questions that warrant further investigation.

\section{The APP Ectodomain}

Various subdomains can be assigned to the APP extracellular sequences based on its primary sequences and structural studies (Figure 1) (reviewed in [89,90]). These include the E1 domain, which consists of the N-terminal growth factor-like domain (GFLD) and the metal (copper and zinc) binding motif, the KPI domain present in APP751 and APP770 isoforms, and the E2 domain which includes the RERMS sequence and the extracellular matrix components. We address below the functional studies associated with the APP extracellular domain.

\section{a) Synaptotrophic and Neuroprotective Functions}

A number of publications have pointed to a neurotrophic role of the APP extracellular domain in both physiological and pathological settings, and this function may be linked to its adhesive properties described above either in its full-length form or as a secreted molecule (i.e. APPs) following ectodomain shredding. Thus, APP may exert these activities in both autocrine and paracrine fashions. Of note, APP undergoes rapid anterograde transport and is targeted to the synaptic sites [16,91-93], where levels of secreted APP coincide with synaptogenesis [94]. APP expression is upregulated during neuronal maturation and differentiation $[95,96]$. Its expression is also induced during traumatic brain injury both in the mammalian system and in Drosophila [18,97-99].

The crystal structure of the E1 domain shows similarities to known cysteine-rich growth factors and thus this domain in the N-terminus of APP has been linked to growth factor-like domain (GFLD) that is seen in the epidermal growth factor receptor [100]. One of the earliest indications of APP function came from the observation that assessing fibroblasts treated with an antisense APP construct grew slower and the growth retardation can be restored by treatment with secreted APPs [101]. The active domain was subsequently mapped to a pentapeptide domain "RERMS" in the E2 
domain [102]. The activity is not limited to fibroblasts as infusion of this pentapeptide or APPs $\alpha$ into the brain resulted in increased synaptic density and better memory retention, while injection of APP antibodies directly into the brain led to impairment in behavioral tasks in adult rat [103]. Application of APPs $\alpha$ resulted in reduced neuronal apoptosis and improved functional recovery following traumatic brain injury (TBI) [103-105]; it also antagonized dendritic degeneration and neuronal death triggered by proteasomal stress [106]. These findings are corroborated by additional reports showing that reduction or loss of APP is associated with impaired neurite outgrowth and neuronal viability in vitro and synaptic activity in vivo [107-109]. Recent studies have further substantiated these early findings, showing for example that APPs regulates NMDA receptor function, synaptic plasticity and spatial memory [110], and that the growth promoting property may be mediated by the down-regulation of CDK5 and inhibition of tau hyperphosphorylation by APPs $\alpha$ [111]. Finally, a number of studies have reported the effects of APPs $\alpha$ on stem cells. Caille et al. first demonstrated the presence of binding sites for APPs in epidermal growth factor (EGF)-responsive neural stem cells in the subventricular zone in the adult rodent brain [112]. In this context, APPs $\alpha$ acts as a co-factor with EGF to stimulate the proliferation of these cells both in neurospheres in culture and in vivo. Subsequently, it was reported that APPs promoted neurite outgrowth in neural stem cells where APLP2 but not APLP1 was redundant to APP [113]. However and intriguingly, stem cells from APP/APLP1/APLP2 triple knockout embryos did not show any defects in neuronal differentiation in vitro [114]. Furthermore, in APP transgenic mice, overexpression of wild type APP resulted in decreased neurogenesis but promoted survival of newly generated cells [115]. At the moment, it is unclear how all these findings can be reconciled in a parsimonious picture of APP trophic functions.

$\mathrm{Li}$ et al. recently uncovered a novel role for APPs to regulate gene expression likely through binding to an unknown receptor [116]. In particular, they identified transthyretin (TTR) and Klotho as downstream targets of APP that are mediated by APPs $\beta$. These targets are of direct relevance to $\mathrm{AD}$ as TTR has been shown to bind and sequester $A \beta$ [117-119], and Klotho has been extensively implicated in the aging process [120-122]. The regulation of TTR and Klotho expression by APPs $\beta$ offers the intriguing possibility for a self-protective mechanism in the APP processing pathway to counter the production and toxicity of $A \beta$ during aging. Because APPs levels have been reported to be reduced in individuals with AD [123-126], the results support the view that the loss of trophic activity or the defence mechanism of APPs may contribute at least in part to the neurodegeneration in AD.

Lastly and perhaps related to the growth promoting property of APP, an area that has come to light concerning APP function involves carcinogenesis, coinciding with the recent observation of an inverse association between cancer and AD [127]. Previous studies have reported an up-regulation of APP in various solid tumors. The reason for this is unclear but a recent study demonstrated that APP plays a role in growth of cancer cells [128]. Whether this potential tumorigenic activity involves adhesion, trophic properties of APPs, or cell signaling remain to be established.

\section{b) Axonal Pruning and Degeneration}

Whereas ample evidence support a role of APPs $\alpha$ in synaptotrophic and neuroprotective activities, APPs $\beta$ is known to be much less active or even toxic (reviewed in [129]). The differential activities between APPs $\alpha$ and APPs $\beta$ are difficult to comprehend considering that there are only 17 amino acid differences between the two isoforms and sequences implicated in trophic activities are mapped outside this region and common to both isoforms. The most striking finding related to differences between APPs $\alpha$ and APPs $\beta$ came from Nikolaev et al. who reported that, under trophic withdrawal conditions, APPs $\beta$ but not APPs $\alpha$ undergoes further cleavage to produce an $\mathrm{N}$-terminal $\sim 35 \mathrm{kDa}$ derivative (N-APP), which binds to DR6 death receptor and mediates axon pruning and degeneration [130]. The authors attempted to link this pathway to both axonal pruning during normal neurodevelopment and neurodegeneration occurring in AD. However, by using recombinant APPs $\beta$ in vitro and by creating $A P P s \beta$ knockin mice in vivo [116], Li et al. demonstrate that APPs $\beta$ is highly stable and that APPs $\beta$ fails to correct the nerve sprouting phenotype of the APP/APLP2 null neuromuscular synapses (discussed in detail under "APP knockin mice"). Therefore, the biological and pathogenic relevance of the APPs $\beta$ /DR6 pathway outside of the trophic withdrawal paradigm requires further examination.

\section{The APP Intracellular Domain}

The high degree of sequence conservation between the intracellular domains of APP proteins predicts that it is a critical domain mediating APP function. Indeed, this relatively short cytoplasmic domain of 47 amino acid residues contains one well described phosphorylation site as well as multiple functional motifs and multiple binding partners that contribute to trafficking, metabolism, and possibly cell signaling functions of APP.

\section{a) Phosphorylation and Protein-Protein Interaction}

APP can be phosphorylated at multiple sites in both extracellular and intracellular domains (reviewed by 
[131]). Among these, the phosphorylation at the threonine residue within the $\mathrm{VT}^{668}$ PEER motif $\left(\mathrm{Thr}^{668}\right)$ in the APP intracellular domain (Figure 1) has received most of the attention. Several kinases have been implicated in this phosphorylation event, including cyclin-dependent kinase 5 (CDK5), c-Jun N-terminal kinase 1 (JNK1) and JNK3, CDK1/CDC2 kinase and GSK3 $\beta$ [132-135]. Phosphorylation at this residue has been reported to result in several outcomes. First, it has been implicated to regulate APP localization to the growth cones and neurites $[134,136]$, a finding consistent with the preferential transport of Thr ${ }^{668}$ phosphorylated APP to nerve terminals [137]. Second, phosphorylation at $\mathrm{Thr}^{668}$ has been reported to contribute to $A \beta$ generation, a finding consistent with an increase of $\mathrm{Thr}^{668}$ phosphorylated APP fragments in brains of AD individuals [138]. Third, $\mathrm{Thr}^{668}$ phosphorylation leads to resistance of APP to be cleaved by caspases between $\mathrm{Asp}^{664}$ and $\mathrm{Ala}^{665}$ residues, an event that has been proposed to result in increased vulnerability to neuronal death (see below). Fourth, phosphorylation at $\mathrm{Thr}^{668}$ leads to a conformational change in the APP cytoplasmic domain such that interaction with the cytoplasmic adaptor Fe65 through the distal YENPTY motif [139] is altered, thereby affecting the proposed nuclear signaling activity of the APP-Fe65 complex [140]. As the YENPTY motif has been shown to bind several other cytosolic adaptor proteins, it is not surprising then that $\operatorname{Thr}^{668}$ phosphorylation has also been reported to modulate APP interaction with Mint1/X11a [141]. Lastly, following phosphorylation, it has been shown that the peptidyl-propyl cis/trans isomerase Pin 1 catalyzes the cis to trans isomerization of the $\mathrm{Thr}^{668}$-Pro ${ }^{669}$ bond and this is predicted to alter APP conformation [142], possibly related to the Fe65 or Mint-1/X11a interaction with APP. In support of this idea, it was shown that loss of Pin1 in mice resulted in accumulation of hyperphosphorylated tau and increased A $\beta$ levels [142,143], two features that should accelerate AD pathology in the brain. Nevertheless, knockin mice replacing the Thr668 with a non-phosphorylatable Ala residue did not result in substantive changes in either APP localization or in the levels of $\mathrm{A} \beta$ in brain [144], raising the question whether $\mathrm{Thr}^{668}$ phosphorylation plays a significant role in regulating APP trafficking and A $\beta$ generation in vivo.

In addition to $\mathrm{Thr}^{668}$ phosphorylation, the highly conserved APP intracellular domain has been shown to bind to numerous proteins (reviewed in $[145,146])$. Of particular interest and relevance to this review, the $\mathrm{Y}^{682}$ ENPTY motif is required to interact with various adaptor proteins, including Mint-1/X11a (and the family members Mint-2 and Mint-3, so named for their ability to interact with Munc18), Fe65 (as well as Fe65 like proteins Fe65L1 and Fe65L2) and c-Jun N-terminal kinase
(JNK)-interacting protein (JIP), through the phosphotyrosine-binding (PTB) domain. The $\mathrm{Y}^{682}$ has been shown to modulate APP processing in vivo [147]. Of interest is the finding that Fe65 acts as a functional linker between APP and LRP (another type I membrane protein containing two NPXY endocytosis motifs) in modulating endocytic APP trafficking and amyloidogenic processing [148].

\section{b) Apoptosis}

In contrast to the trophic activities of the soluble APP ectodomain, there are also a number of papers demonstrating the cytotoxic properties of $\beta$-secretase cleaved APP CTF (or C99), especially following overexpression [149-151]. The mechanism by which APP CTF is cytotoxic is unclear but one pathway may be through AICD released from APP CTF following $\varepsilon$-cleavage. Normally, AICD exists in very low levels in vivo but can be stabilized when Fe65 is overexpressed [152-154]. In cultured cells, overexpression of AICD led to cell death [154-156]. In transgenic mice overexpressing an AICD construct, there was activation of GSK-3 $\beta$ but no overt neuronal death $[157,158]$, findings not replicated in a subsequent study however [159]. Interestingly, in mice expressing both AICD and Fe65, neuronal degeneration was observed in old mice together with tau hyperphosphorylation. Furthermore, behavioral abnormalities seen in these animals can be rescued by treatment with lithium, a GSK-3 $\beta$ inhibitor, in line with earlier evidence of activation of GSK-3 3 [160].

Another aspect of APP CTF mediated cytotoxicity concerns a caspase cleavage site within the cytosolic tail between position $\mathrm{Asp}^{664}$ and $\mathrm{Ala}^{665}$ [161]. In cell culture systems, loss of this caspase site by mutating the Asp ${ }^{664}$ to Ala (D664A) resulted in an attenuation of APP C99 associated cytotoxicity. It has been proposed that release of the smaller fragments (C31 and Jcasp) from AICD after cleavage at position 664 results in the generation of new cytotoxic APP related peptides [162]. Thus, overexpression of either C31 or Jcasp, both derived from AICD, have resulted in cytotoxicity. Consistent with these in vitro findings, in an APP transgenic mouse line in which the caspase site is mutated to render APP noncleavable, the predicted $A \beta$-related phenotypes in brain (synaptic, behavior, and electrophysiological abnormalities) were absent in spite of abundant amyloid deposits $[163,164]$. Therefore, these initial observations indicated that the release of the smaller fragments (C31 or Jcasp) after caspase cleavage of C99 may result in cell death in a manner independent of $\gamma$-secretase [165]. However, analysis of another line of APP D664A transgenic mice with substantially higher APP expression failed to replicate the earlier findings [166], but the wide differences in expression of the transgene and resultant $A \beta$ levels between the two transgenic mouse lines is such that the 
comparisons may be invalid [167]. In sum, there are at present several potential mechanisms whereby APP may contribute to neurotoxicity: via $\gamma$-secretase cleavage to release AICD or via alternative cleavage of the APP $\mathrm{C}$-terminus to release other cytotoxic peptides. Whether these APP fragments contribute to in vivo neuronal death in AD pathogenesis remain to be established.

\section{c) Cell Signaling}

As mentioned previously, in addition to $\gamma$-secretase cleavage that yields $A \beta 40$ and $A \beta 42$, presenilin-dependent proteolysis appears to begin at the $\varepsilon$-site $(\mathrm{A} \beta 49)$ close to the membrane-intracellular boundary $[46,48,49]$. Thus the $\varepsilon$-cleavage of APP may represent the primary or initial presenilin-dependent processing event. This is important because this cleavage releases AICD in a manner highly reminiscent of the release of the Notch intracellular domain (NICD) after $\gamma$-secretase processing, the latter being an obligatory step in Notch mediated signaling (reviewed in [59]). The predominant $\varepsilon$-cleavage releases AICD of 50 amino acids in length (CTF50-99), beginning with a Val residue. APP mutations that shift $A \beta$ production in favor of $A \beta 42$ would lengthen the AICD by one amino acid (CTF 49-99), now beginning with a Leu residue. This is of some interest because it has been pointed out that the $\mathrm{N}$-end rule guiding protein stability through ubiquitination states that Val is a stabilizing residue while Leu is destabilizing (Reviewed in [168]). NICD, the intracellular domain derived from the Notch receptor, appears to follow this principle experimentally. If this situation applies to AICD, then there could be a different regulatory mechanism at play regarding AICD mediated cell signaling or in cell death. Furthermore, recent studies have suggested that AICD generation is in part dependent on whether APP was previously cleaved by $\alpha$ - or $\beta$-secretase, indicating yet another layer of regulation $[169,170]$. Nonetheless, AICD is indeed very labile and, as mentioned previously, can be stabilized by Fe65 [153], a finding seen both in the in vitro and in vivo settings. A good deal of excitement followed the first report in which by using a heterologous reporter system, AICD was shown to form a transcriptionally active complex together with Fe65 and Tip60 [157,171]. This finding appeared to validate the notion that AICD is transcriptionally active, much like NICD. Scheinfeld et al. proposed a JIP-1 dependent transcriptional activity of AICD [172]. However, subsequent analyses have suggested that the earlier view may be too simplistic and incomplete. First, follow up studies by Cao et al. showed that AICD facilitates the recruitment of Fe65 but its nuclear translocation per se is not required [173]. Second, PS-dependent AICD production is not a prerequisite for the APP signaling activity, as it proceeds normally in PS null cells and by PS inhibitor treatment [174]. Instead, the authors provide an alternative pathway for this activity that involves Tip60 phosphorylation. Third, a later report documented that the proposed signaling activity is actually executed by Fe65 and that APP is not required altogether [175]. Lastly, Giliberto et al. reported that mice transgenic for AICD in neuronal cells are more susceptible to apoptosis. However, analysis of the basal transcription showed little changes in mice expressing AICD in the absence of Fe65 overexpression, leaving open the possibility that transcription may be influenced in a regulated fashion [176].

Regardless of the mechanism by which AICD may activate signaling pathways, a trans-activating role of the APP/Fe65/Tip60 complex has been consistently documented, at least in overexpression systems. However, these efforts have led to decidedly mixed results. A number of genes have been proposed to date including KAI [177], GSK3 $\beta$ [158,178], neprilysin [179], EGFR [180], p53 [181], LRP [182], APP itself [183], and genes involved in calcium regulation [184] and cytoskeletal dynamics [185]. However, the validity of these proposed targets have been either questioned or disputed $[175,176,186-190]$. Thus, at present, a conservative view is that these target genes are indirectly or only weakly influenced by AICD mediated transcriptional regulation.

\section{E. In vivo Function of APP}

The in vivo gain- and loss-of-function phenotypes associated with the APP family of proteins in model systems (C. elegans, Drosophila and mice) are consistent with a role of APP in neuronal and synaptic function in both central and peripheral nervous systems. This may be mediated by the APP ectodomain or requires the APP intracellular domain. These findings will be discussed next in the respective animal models.

\section{a) C. elegans}

The C. elegans homolog of APP, APL-1, resembles the neuronal isoform APP695 as there are no known splice variants detected. Similar to APLP1 and APLP2, APL-1 does not contain the $A \beta$ sequence. Nematode development includes four larval stages (L1-L4) after each of which is a molt where a new, larger exoskeleton is formed to accommodate the growth of the larvae. Inactivation of the single apl-1 gene leads to developmental arrest and lethality at the L1 stage, likely due to a molting defect $[191,192]$. In addition, apl-1 knockdown leads to hypersensitivity to the acetylcholinesterase inhibitor aldicarb, signifying a defect in neurotransmission [192]. The aldicarb hypersensitivity phenotype and the molting defect were found to be independent of one another, suggesting apl-1 contributes to multiple functions within the worm. Surprisingly, both phenotypes were rescued by either a membrane-anchored C-terminal truncation of APL-1 or by the soluble N-terminal 
fragments, showing that the highly conserved C-terminus is not required to support the viability of the worm $[191,192]$. This differs from the mammalian system in which the APP C-terminus is essential for viability on a non-redundant background (see discussion under "APP knock-in mice") [116,193]. Although the reason for the distinct domain requirement for C. elegans and mouse viability is not clear, it is worth reiterating that the lethality of the apl-1 null worm is likely caused by a molting defect not relevant to mammals. Consistent with this interpretation, it is interesting that expression of mammalian APP or its homologs are not able to rescue the apl-1 null lethality [191,192], indicating that this wormspecific molting activity is lost during mammalian evolution and that extrapolation of APP function from apl-1 may not be very informative.

\section{b) Drosophila}

The Drosophila APP homolog, APPL, like the worm homolog, does not contain the $A \beta$ sequence and does not undergo alternative splicing. However, in contrast to the apl-1 null worm, Appl-deficient flies are viable with only subtle behavioral defects such as fast phototaxis impairment [3]. While human APP is not able to rescue the C. elegans apl-1 lethality, the behavioral phenotype present in the Appl null fly can be partially rescued by transgenic expression of either fly APPL or human APP [3]. Subsequent loss and gain-of-function studies revealed that APPL plays an important role in axonal transport, since either Appl deletion or overexpression caused axonal trafficking defects similar to kinesin and dynein mutants [194,195]. Although a similar role for APP in axonal transport of selected cargos has been reported [196-198], the findings have since been challenged by several laboratories [199].

APPL is required for the development of neuromuscular junctions (NMJs), since Appl deletion leads to decreased bouton number of NMJs, whereas Appl overexpression dramatically increases the satellite bouton number [200]. This activity can be explained by the formation of a potential complex including APPL, the APPL-binding protein $\mathrm{dX} 11 /$ Mint, and the cell adhesion molecule FasII, which together regulate synapse formation [201]. Overexpression of human APP homologs in Drosophila revealed a spectrum of other phenotypes, ranging from 1) a blistered wing phenotype that may involve cell adhesion [202], 2) a Notch gain-of-function phenotype in mechano-sensory organs, which reveals a possible genetic interaction of APP and Notch through Numb [203], and 3) a neurite outgrowth phenotype that is linked to the Abelson tyrosine kinase and JNK stress kinase [99]. Although the pathways implicated in each of the phenotypes are distinct, they all seem to require the APP intracellular domain via protein-protein interactions mediated through the conserved YENPTY sequence. These ectopic overexpression studies should be interpreted with caution because APP interacts with numerous adaptor proteins and many of the APP binding partners also interact with other proteins. Therefore, the phenotypes observed by overexpressing APP or APPL could be caused by the disturbance of a global protein-protein interaction network.

Interestingly, similar to the mammalian system, APPL is found to be upregulated in traumatic brain injury and Appl-deficient flies suffer a higher mortality rate compared to controls [99], supporting an important activity of APP family of proteins in nerve injury response and repair.

c) Mice

i. APP single knockout mice Three mouse APP alleles, one carrying a hypomorphic mutation and two with complete deficiencies of $A P P$ have been generated [204-206]. The APP null mice are viable and fertile but exhibit reduced body weight and brain weight. Loss of APP results in a wide spectrum of central and peripheral neuronal phenotypes including reduced locomotor activity [204,205,207], reactive gliosis [205], straindependent agenesis of the corpus callosum [205,208], and hypersensitivity to kainate induced seizures [209]. Although these phenotypes indicate a functional role of APP in the CNS, the molecular mechanisms mediating these effects remain to be established. Unbiased stereology analysis failed to reveal any loss of neurons or synapses in the hippocampus of aged $A P P$ null mice [210]. Attempts to examine spine density in APP KO mice have yielded mixed results. Using hippocampal autaptic cultures, Priller et al. reported an enhanced excitatory synaptic response in the absence of $A P P$, and the authors attributed this effect to the lack of $A \beta$ production [211]. Follow up studies by the same group reported that $A P P$ deletion led to a two-fold higher dendritic spine density in layers III and V of the somatosensory cortex of 4-6 month-old mice [212]. However, Lee et al. found a significant reduction in spine density in cortical layer II/III and hippocampal CA1 pyramidal neurons of one-year old APP KO mice compared with WT controls [213]. It is not clear whether differences in age or brain region may contribute to the discrepancy.

The APP null mice show impaired performances in Morris water maze and passive avoidance tasks, and the behavioral deficits are associated with a defect in long term potentiation (LTP) [207,210,214,215], the latter may be attributed to an abnormal GABAergic paired pulse depression [215]. Follow up work demonstrated that APP modulates GABAergic synaptic strength by regulating Cav1.2 L-type calcium channel (LTCC) expression and function in stratial and hippocampal GABAergic neurons [216]. APP deficiency leads to an increase in the levels of $\alpha 1 C$, the pore forming subunit 
of Cav1.2 LTCCs and an enhanced Ca2+ current, which in turn results in reduced GABAergic mediated pairedpulse inhibition and increased GABAergic post-tetanic potentiation [216]. A role of APP in calcium regulation is further documented by APP overexpression and knockdown studies in hippocampal neurons which support an A $\beta$ independent role of APP in the regulation of calcium oscillations [217].

Outside of the CNS, APP deficient mice display reduced grip strength $[205,207]$. This is likely due to impaired $\mathrm{Ca}^{2+}$ handling at the neuromuscular junction (NMJ) as functional recordings revealed that APP null mice show abnormal paired pulse response and enhanced asynchronous release at NMJ resulting from aberrant activation of voltage gated $\mathrm{N}$ - and L-type calcium channels at motor neuron terminals [218]. Taken together, the studies thus provide strong support for the notion that APP plays an important role in $\mathrm{Ca}^{2+}$ homeostasis and calcium-mediated synaptic responses in a variety of neurons, including GABAergic and cholinergic neurons and possibly others, through which it may regulate the neuronal network and cognitive function.

ii. APP, APLP1, APLP2 compound knockout mice The relatively subtle phenotypes of $A P P$ deficient mice are likely due to genetic redundancies as evidenced by gene knockout studies. While mice with individual deletion of $A P P, A P L P 1$ and $A P L P 2$ are viable, $A P P / A P L P 2$ and $A P L P 1 / A P L P 2$ double knockout mice or mice deficient in all three APP family members are lethal in the early postnatal period $[219,220]$. Intriguingly and due to reasons not well understood, the APP/APLP1 double null mice are viable [220]. Although the NMJ of $A P P$ or $A P L P 2$ single null mice do not show overt structural abnormalities, the APP/APLP2 double knockout animals exhibit poorly formed neuromuscular synapses with reduced apposition of presynaptic proteins with postsynaptic acetylcholine receptors and excessive nerve terminal sprouting [221]. The number of synaptic vesicles at the presynaptic terminals is reduced, a finding consistent with defective neurotransmitter release. Examination of the parasympathetic submandibular ganglia of the double deficient animals also showed a reduction in active zone size, synaptic vesicle density, and number of docked vesicles per active zone [222].

Interestingly, tissue-specific deletion of $A P P$ either in neurons or in muscle on APLP2 knockout background resulted in neuromuscular defects similar to those seen in global $A P P / A P L P 2$ double null mice, demonstrating that APP is required in both motoneurons and muscle cells for proper formation and function of neuromuscular synapses [80]. The authors propose that this is mediated by a trans-synaptic interaction of APP, a model that gained support by hippocampal and HEK293 mixed culture assays described above [80]. Interestingly, muscle
APP expression is required for proper presynaptic localization of $\mathrm{CHT}$ and synaptic transmission, suggesting that trans-synaptic APP interaction is necessary in recruiting presynaptic APP/CHT complex [80,223].

Analysis of $A P P / A P L P 1 / A P L P 2$ triple knockout mice revealed that the majority of the animals showed cortical dysplasia suggestive of neuronal migration abnormalities and partial loss of cortical Cajal Retzius cells [224]. Interestingly, this defect is phenocopied in mice doubly deficient in APP binding proteins Fe65 and Fe65L1 [225]. It should be pointed out however, that morphological similarity does not necessarily implicate functional interaction. Indeed, cortical dysplasia with viable penetrance also exists in mice deficient in various other proteins including PS1, $\beta 1$ and $\alpha 6$ integrins, focal adhesion kinase, $\alpha$-dystroglycan and laminin $\alpha 2$ (reviewed in [226]).

In sum, the loss-of-function studies present a convincing picture that members of the $A P P$ gene family play essential roles in the development of the peripheral and central nervous systems relating to synapse structure and function, as well as in neuronal migration or adhesion. These may be mediated either by the full-length protein or by various proteolytic processing products, and may be due to mechanical properties or through activating signaling pathways, or both. The creation of knockin alleles expressing defined proteolytic fragments of APP offers a powerful system to delineate the APP functional domains in vivo. These are discussed in the following section.

iii. APP Knock-in mice To date, four APP domain knock-in alleles have been reported and these express $\alpha$ secretase (APPs $\alpha$ [227]) or $\beta$-secretase (APPs $\beta$ [116]) processed soluble APP, the membrane anchored protein with deletions of either the last 15 aa (APP $\triangle \mathrm{CT} 15$ [227]) or 39 aa $(\mathrm{APP} / \mathrm{hA} \beta / \mathrm{mutC}$ [193]) of the highly conserved $\mathrm{C}$-terminal sequences of APP, the latter also replaced mouse $A \beta$ with the human sequence and introduced three FAD mutations (Swedish, Arctic, and London) to facilitate A $\beta$ production. The APPs $\alpha$ and APP $\triangle$ CT15 knock-in mice appeared to rescue a variety of phenotypes observed in APP KO mice [227]. For instance, the reduced body and brain weight of $A P P$ null animals was largely rescued. Behaviorally, the knock-in mice do not exhibit any defects in grip strength or the Morris water maze test. Field recordings of hippocampal slices showed that the LTP deficits observed in 9-12 month-old APP $\mathrm{KO}$ mice was also absent in both knock-in lines. These findings are in agreement with the large body of literature documenting the synaptotrophic activity of APPs $\alpha$ (refer to "Synaptotrophic and Neuroprotective Functions" above) and that perhaps the predominant function of APP is mediated by APPs $\alpha$.

Similar to APPs $\alpha$ and APP $\triangle \mathrm{CT} 15$ knock-in lines, the $\mathrm{APPs} \beta$ and APP/hA $\beta /$ mutC mice did not show any overt 
growth or anatomatical deficits. However and in stark contrast to the aforementioned two knockin mouse lines, crossing these two alleles (APPs $\beta$ or anchored APP/hA $\beta$ / mutC) to $A P L P 2^{-1-}$ background failed to rescue the early postnatal lethality and neuromuscular synapse defects of the APP/APLP2 KO mice [116,193], suggesting a critical and indispensable role of the conserved $C$-terminal region of APP in early postnatal development. An essential role of the APP C-terminal domain, specifically the YENPTY motif, in development was demonstrated by the creation of APP knock-in mice in which the $\mathrm{Tyr}^{682}$ residue of the $\mathrm{Y}^{682}$ ENPTY sequence was changed to Gly $\left(\mathrm{APP}^{\mathrm{YG}}\right)$. Crossing the homozygous knock-in mice to $A P L P 2$ null background showed that the $A P P^{\mathrm{YG} / \mathrm{YG}}$ / $A P L P 2^{-1-}$ mice exhibit neuromuscular synapse deficits and early lethality similar to $A P P / A P L P 2$ double $\mathrm{KO}$ mice [228]. The differences in outcomes in these experiments are difficult to explain but may be related to a more severe phenotype in the APLP2 deficient background. Nevertheless, the inability to rescue the NMJ defects by the APP mutants lacking the intracellular domain or expressing the $\mathrm{Tyr}^{682}$ to Gly mutation is compatible with the concept that APP functions as a synaptic adhesion protein. Furthermore, the fact that amyloid deposition can develop in the absence of the APP Cterminal sequences indicates that APP developmental function and amyloidogenesis are differentially regulated and require distinct APP domains [193].

\section{Concluding Remarks}

We hope this review has provided a timely update on what is known and what lies ahead in the field of APP biology. Since the first identification of the APP gene in 1987, the scientific community has worked together to obtain significant insights into the biochemical, cellular and functional properties of APP. It is clear that APP undergoes tightly regulated trafficking and processing and, through either the full-length protein and/or its cleavage products, it mediates synaptogenic and synapotrophic activities in development and during aging. As such, it is reasonable to speculate that misregulation of APP could contribute to the neuronal and synaptic impairment occurring in AD. Many key questions remain to be addressed. These include determining whether APP is a receptor or a ligand and, accordingly, the identities of its respective ligand or receptor. Does APP directly mediate cell signaling or only play a secondary role in gene expression? How is APP function coordinated between its full-length form and the various processing products, and how is it facilitated through its binding partners? Elucidating these questions will undoubtedly reveal novel insights into disease pathogenesis.

\section{Acknowledgements}

The authors' work cited in this review was supported by grants from $\mathrm{NIH}$ (AG032051 and AG033467 to HZ AG020206 and AG032179 to EHK), and the American Health and Assistance Foundation (to $\mathrm{HZ}$ ).

\section{Author details}

${ }^{1}$ Huffington Center on Aging and Department of Molecular \& Human

Genetics, Baylor College of Medicine, Houston, TX 77030, USA. ²Department of Neurosciences, University of California, San Diego, La Jolla, CA 92093, USA.

\section{Authors' contributions}

$\mathrm{HZ}$ and $\mathrm{EHK}$ wrote the manuscript. $\mathrm{HZ}$ made the figures. Both authors have read and approved the final manuscript.

\section{Competing interests}

The authors declare that they have no competing interests.

Received: 13 February 2011 Accepted: 28 April 2011

Published: 28 April 2011

\section{References}

1. Daigle I, Li C: apl-1, a Caenorhabditis elegans gene encoding a protein related to the human beta-amyloid protein precursor. Proc Natl Acad Sci USA 1993, 90(24):12045-9.

2. Rosen DR, et al: $A$ Drosophila gene encoding a protein resembling the human beta-amyloid protein precursor. Proc Natl Acad Sci USA 1989, 86(7):2478-82.

3. Luo L, Tully $T$, White $K$ : Human amyloid precursor protein ameliorates behavioral deficit of flies deleted for Appl gene. Neuron 1992, 9(4):595-605.

4. Musa A, Lehrach $H$, Russo VA: Distinct expression patterns of two zebrafish homologues of the human APP gene during embryonic development. Dev Genes Evol 2001, 211(11):563-7.

5. Okado H, Okamoto $H$ : A Xenopus homologue of the human betaamyloid precursor protein: developmental regulation of its gene expression. Biochem Biophys Res Commun 1992, 189(3):1561-8.

6. van den Hurk WH, Bloemen M, Martens GJ: Expression of the gene encoding the beta-amyloid precursor protein APP in Xenopus laevis. Brain Res Mol Brain Res 2001, 97(1):13-20.

7. Goldgaber D, et al: Characterization and chromosomal localization of a CDNA encoding brain amyloid of Alzheimer's disease. Science 1987, 235(4791):877-80.

8. Tanzi RE, et al: Amyloid beta protein gene: CDNA, mRNA distribution, and genetic linkage near the Alzheimer locus. Science 1987, 235(4791):880-4.

9. Wasco W, et al: Identification of a mouse brain CDNA that encodes a protein related to the Alzheimer disease-associated amyloid beta protein precursor. Proc Natl Acad Sci USA 1992, 89(22):10758-62.

10. Wasco W, et al: Isolation and characterization of APLP2 encoding a homologue of the Alzheimer's associated amyloid beta protein precursor. Nat Genet 1993, 5(1):95-100.

11. Slunt $\mathrm{HH}$, et al: Expression of a ubiquitous, cross-reactive homologue of the mouse beta-amyloid precursor protein (APP). J Biol Chem 1994, 269(4):2637-44.

12. Collin RW, et al: Identification and expression of the first nonmammalian amyloid-beta precursor-like protein APLP2 in the amphibian Xenopus laevis. Eur J Biochem 2004, 271(10):1906-12.

13. Martin-Morris LE, White K: The Drosophila transcript encoded by the betaamyloid protein precursor-like gene is restricted to the nervous system. Development 1990, 110(1):185-95.

14. Yoshikai $\mathrm{S}$, et al: Genomic organization of the human amyloid betaprotein precursor gene [published erratum appears in Gene 1991 Jun 30;102(2):291-2]. Gene 1990, 87(2):257-63.

15. Lamb BT, et al: Introduction and expression of the 400 kilobase amyloid precursor protein gene in transgenic mice [corrected] [published erratum appears in Nat Genet 1993 Nov;5(3):312]. Nat Genet 1993, 5(1):22-30.

16. Sisodia SS, et al: Identification and transport of full-length amyloid precursor proteins in rat peripheral nervous system. J Neurosci 1993, 13(7):3136-42. 
17. Siman R, et al: Expression of beta-amyloid precursor protein in reactive astrocytes following neuronal damage. Neuron 1989, 3(3):275-85.

18. Van Den Heuvel C, et al: Upregulation of amyloid precursor protein and its mRNA in an experimental model of paediatric head injury. J Clin Neurosci 2000, 7(2):140-5

19. De Strooper B, Annaert W: Proteolytic processing and cell biological functions of the amyloid precursor protein [In Process Citation]. J Cell Sci 2000, 113(Pt 11):1857-70

20. Vassar R, et al: Beta-secretase cleavage of Alzheimer's amyloid precursor protein by the transmembrane aspartic protease BACE. Science 1999, 286(5440):735-41

21. Yan R, et al: Membrane-anchored aspartyl protease with Alzheimer's disease beta-secretase activity [see comments]. Nature 1999, 402(6761):533-7.

22. Sinha $\mathrm{S}$, et al: Purification and cloning of amyloid precursor protein betasecretase from human brain [see comments]. Nature 1999, 402(6761):537-40.

23. Cai $\mathrm{H}$, et al: BACE1 is the major beta-secretase for generation of Abeta peptides by neurons. Nat Neurosci 2001, 4(3):233-4.

24. Luo Y, et al: Mice deficient in BACE1, the Alzheimer's beta-secretase, have normal phenotype and abolished beta-amyloid generation. Nat Neurosci 2001, 4(3):231-2

25. Huse JT, et al: Beta-secretase processing in the trans-Golgi network preferentially generates truncated amyloid species that accumulate in Alzheimer's disease brain. J Biol Chem 2002, 277(18):16278-84.

26. Solans A, Estivill X, de La Luna S: A new aspartyl protease on 21q22.3, BACE2, is highly similar to Alzheimer's amyloid precursor protein betasecretase. Cytogenet Cell Genet 2000, 89(3-4):177-84.

27. Yan $R$, et al: BACE2 functions as an alternative alpha-secretase in cells J Biol Chem 2001, 276(36):34019-27.

28. Hook $V$, et al: Inhibition of cathepsin B reduces beta-amyloid production in regulated secretory vesicles of neuronal chromaffin cells: evidence for cathepsin B as a candidate beta-secretase of Alzheimer's disease. Biol Chem 2005, 386(9):931-40.

29. Hook VY, Kindy M, Hook G: Inhibitors of cathepsin B improve memory and reduce beta-amyloid in transgenic Alzheimer disease mice expressing the wild-type, but not the Swedish mutant, beta-secretase site of the amyloid precursor protein. J Biol Chem 2008, 283(12):7745-53.

30. Roberds $S L$, et al: BACE knockout mice are healthy despite lacking the primary beta-secretase activity in brain: implications for Alzheimer's disease therapeutics. Hum Mol Genet 2001, 10(12):1317-24

31. Lichtenthaler SF: Alpha-secretase in Alzheimer's disease: molecular identity, regulation and therapeutic potential. J Neurochem 116(1):10-21.

32. Buxbaum JD, et al: Evidence that tumor necrosis factor alpha converting enzyme is involved in regulated alpha-secretase cleavage of the Alzheimer amyloid protein precursor. J Biol Chem 1998, 273(43):27765-7.

33. Blacker $M$, et al: Effect of tumor necrosis factor-alpha converting enzyme (TACE) and metalloprotease inhibitor on amyloid precursor protein metabolism in human neurons. J Neurochem 2002, 83(6):1349-57.

34. Kuhn PH, et al: ADAM10 is the physiologically relevant, constitutive alpha-secretase of the amyloid precursor protein in primary neurons. EMBO J 29(17):3020-32

35. Donmez G, et al: SIRT1 suppresses beta-amyloid production by activating the alpha-secretase gene ADAM10. Cell 142(2):320-32.

36. Gowing E, et al: Chemical characterization of A beta 17-42 peptide, a component of diffuse amyloid deposits of Alzheimer disease. J Biol Chem 1994, 269(15):10987-90

37. Lalowski M, et al: The "nonamyloidogenic" p3 fragment (amyloid beta1742) is a major constituent of Down's syndrome cerebellar preamyloid. J Biol Chem 1996, 271(52):33623-31.

38. Tekirian $\mathrm{TL}$, et al: $\mathrm{N}$-terminal heterogeneity of parenchymal and cerebrovascular Abeta deposits. J Neuropathol Exp Neurol 1998, 57(1):76-94.

39. Wei W, et al: Abeta 17-42 in Alzheimer's disease activates JNK and caspase-8 leading to neuronal apoptosis. Brain 2002, 125(Pt 9):2036-43.

40. Szczepanik AM, Rampe D, Ringheim GE: Amyloid-beta peptide fragments p3 and p4 induce pro-inflammatory cytokine and chemokine production in vitro and in vivo. J Neurochem 2001, 77(1):304-17.

41. Edbauer D, et al: Reconstitution of gamma-secretase activity. Nat Cell Biol 2003, 5(5):486-8.
42. Iwatsubo $\mathrm{T}$ : The gamma-secretase complex: machinery for intramembrane proteolysis. Curr Opin Neurobiol 2004, 14(3):379-83.

43. Wolfe MS, et al: Two transmembrane aspartates in presenilin-1 required for presenilin endoproteolysis and gamma-secretase activity [In Process Citation]. Nature 1999, 398(6727):513-7.

44. Ahn K, et al: Activation and intrinsic \{gamma\}-secretase activity of presenilin 1. Proc Natl Acad Sci USA 2010, 107(50):21435-40.

45. Zhao G, et al: Identification of a new presenilin-dependent zeta-cleavage site within the transmembrane domain of amyloid precursor protein. J Biol Chem 2004, 279(49):50647-50.

46. Zhao G, et al: \{gamma\}-Cleavage Is Dependent on \{zeta\}-Cleavage during the Proteolytic Processing of Amyloid Precursor Protein within Its Transmembrane Domain. J Biol Chem 2005, 280(45):37689-97, Epub 2005 Sep 12.

47. Sato $T$, et al: Blocking the cleavage at midportion between gamma- and epsilon-sites remarkably suppresses the generation of amyloid betaprotein. FEBS Lett 2005, 579(13):2907-12

48. Sastre $M$, et al: Presenilin-dependent gamma-secretase processing of beta-amyloid precursor protein at a site corresponding to the S3 cleavage of Notch. EMBO Rep 2001, 2(9):835-41.

49. Weidemann $A$, et al: A novel epsilon-cleavage within the transmembrane domain of the Alzheimer amyloid precursor protein demonstrates homology with Notch processing. Biochemistry 2002, 41(8):2825-35.

50. Qi-Takahara $Y$, et al: Longer forms of amyloid beta protein: implications for the mechanism of intramembrane cleavage by gamma-secretase. J Neurosci 2005, 25(2):436-45.

51. Yagishita S, et al: Abeta46 is processed to Abeta40 and Abeta43, but not to Abeta42, in the low density membrane domains. J Biol Chem 2008, 283(2):733-8

52. Yagishita S, et al: DAPT-Induced Intracellular Accumulations of Longer Amyloid beta-Proteins: Further Implications for the Mechanism of Intramembrane Cleavage by gamma-Secretase. Biochemistry 2006, 45(12):3952-60.

53. Takami $\mathrm{M}$, et al: gamma-Secretase: successive tripeptide and tetrapeptide release from the transmembrane domain of beta-carboxyl terminal fragment. J Neurosci 2009, 29(41):13042-52.

54. Annaert WG, Saftig p: Regulated intramembrane proteolysis-a story about sheddases and I-CliPs. Semin Cell Dev Biol 2009, 20(2):125.

55. Hu X, et al: Bace1 modulates myelination in the central and peripheral nervous system. Nat Neurosci 2006, 9(12):1520-5, Epub 2006 Nov 12.

56. Willem $\mathrm{M}$, et al: Control of peripheral nerve myelination by the betasecretase BACE1. Science 2006, 314(5799):664-6, Epub 2006 Sep 21.

57. Wolfe MS, Kopan R: Intramembrane proteolysis: theme and variations. Science 2004, 305(5687):1119-23.

58. Kopan R, llagan MX: Gamma-secretase: proteasome of the membrane? Nat Rev Mol Cell Biol 2004, 5(6):499-504.

59. Selkoe D, Kopan R: Notch and Presenilin: regulated intramembrane proteolysis links development and degeneration. Annu Rev Neurosci 2003, 26:565-97.

60. Lorenzo A, et al: Amyloid beta interacts with the amyloid precursor protein: a potential toxic mechanism in Alzheimer's disease. Nat Neurosci 2000, 3(5):460-4

61. Lu DC, et al: Amyloid beta protein toxicity mediated by the formation of amyloid-beta protein precursor complexes. Ann Neurol 2003, 54(6):781-9.

62. Ho A, Sudhof TC: Binding of F-spondin to amyloid-beta precursor protein: a candidate amyloid-beta precursor protein ligand that modulates amyloid-beta precursor protein cleavage. Proc Natl Acad Sci USA 2004, 101(8):2548-53.

63. Park JH, et al: Alzheimer precursor protein interaction with the Nogo-66 receptor reduces amyloid-beta plaque deposition. J Neurosci 2006, 26(5):1386-95

64. Lourenco FC, et al: Netrin-1 interacts with amyloid precursor protein and regulates amyloid-beta production. Cell Death \& Differentiation 2009, 16(5):655-63

65. Matsuda S, et al: Maturation of BRI2 generates a specific inhibitor that reduces APP processing at the plasma membrane and in endocytic vesicles. Neurobiol Aging 2009.

66. Giliberto $L$, et al: Generation and initial characterization of FDD knock in mice. PLoS One 2009, 4(11):e7900

67. Small $\mathrm{DH}$, et al: Neurite-outgrowth regulating functions of the amyloid protein precursor of Alzheimer's disease. J Alzheimers Dis 1999, 1(4-5):275-85. 
68. Wang $Y, \mathrm{Ha}$ Y: The $X$-ray structure of an antiparallel dimer of the human amyloid precursor protein E2 domain. Mol Cell 2004, 15(3):343-53.

69. Soba $\mathrm{P}$, et al: Homo- and heterodimerization of APP family members promotes intercellular adhesion. Embo J 2005, 24(20):3624-34, Epub 2005 Sep 29.

70. Dahms SO, et al: Structure and biochemical analysis of the heparininduced E1 dimer of the amyloid precursor protein. Proc Natl Acad Sci USA 2010, 107(12):5381-6.

71. Munter LM, et al: GxxxG motifs within the amyloid precursor protein transmembrane sequence are critical for the etiology of Abeta42. EMBO Journal 2007, 26(6):1702-12.

72. Kienlen-Campard $P$, et al: Amyloidogenic processing but not amyloid precursor protein (APP) intracellular C-terminal domain production requires a precisely oriented APP dimer assembled by transmembrane GXXXG motifs. J Biol Chem 2008, 283(12):7733-44.

73. Eggert $S$, et al: Induced dimerization of the amyloid precursor protein leads to decreased amyloid-beta protein production. J Biol Chem 2009, 284(42):28943-52.

74. Kaden D, et al: Subcellular localization and dimerization of APLP1 are strikingly different from APP and APLP2. J Cell Sci 2009, 122(Pt 3):368-77.

75. Ghiso J, et al: A 109-amino-acid C-terminal fragment of Alzheimer'sdisease amyloid precursor protein contains a sequence, -RHDS-, that promotes cell adhesion. Biochem J 1992, 288(Pt 3):1053-9.

76. Storey $E$, et al: The amyloid precursor protein of Alzheimer's disease is found on the surface of static but not activity motile portions of neurites. Brain Res 1996, 735(1):59-66.

77. Yamazaki T, Koo EH, Selkoe DJ: Cell surface amyloid beta-protein precursor colocalizes with beta 1 integrins at substrate contact sites in neural cells. J Neurosci 1997, 17(3):1004-10.

78. Young-Pearse $T L$, et al: Secreted APP regulates the function of full-length APP in neurite outgrowth through interaction with integrin beta1. Neural Dev 2008, 3:15.

79. Young-Pearse $T L$, et al: A critical function for beta-amyloid precursor protein in neuronal migration revealed by in utero RNA interference. J Neurosci 2007, 27(52):14459-69.

80. Wang $Z$, et al: Presynaptic and postsynaptic interaction of the amyloid precursor protein promotes peripheral and central synaptogenesis. J Neurosci 2009, 29(35):10788-801.

81. Scheiffele $P$, et al: Neuroligin expressed in nonneuronal cells triggers presynaptic development in contacting axons. Cell 2000, 101(6):657-69.

82. Graf ER, et al: Neurexins induce differentiation of GABA and glutamate postsynaptic specializations via neuroligins. Cell 2004, 119(7):1013-26.

83. Biederer $T$, et al: SynCAM, a synaptic adhesion molecule that drives synapse assembly. Science 2002, 297(5586):1525-31.

84. Fogel Al, et al: SynCAMs organize synapses through heterophilic adhesion. J Neurosci 2007, 27(46):12516-30.

85. Sara $Y$, et al: Selective capability of SynCAM and neuroligin for functional synapse assembly. J Neurosci 2005, 25(1):260-70.

86. Linhoff MW, et al: An unbiased expression screen for synaptogenic proteins identifies the LRRTM protein family as synaptic organizers. Neuron 2009, 61(5):734-49.

87. Dalva MB, McClelland AC, Kayser MS: Cell adhesion molecules: signalling functions at the synapse. Nat Rev Neurosci 2007, 8(3):206-20, Epub 2007 Feb 14

88. Norstrom EM, et al: Identification of NEEP21 as a ss-amyloid precursor protein-interacting protein in vivo that modulates amyloidogenic processing in vitro. J Neurosci 30(46):15677-85.

89. Mattson MP: Cellular actions of beta-amyloid precursor protein and its soluble and fibrillogenic derivatives. Physiol Rev 1997, 77(4):1081-132.

90. Reinhard C, Hebert SS, De Strooper B: The amyloid-beta precursor protein: integrating structure with biological function. Embo J 2005, 24(23):3996-4006, Epub 2005 Oct 27.

91. Koo EH, et al: Precursor of amyloid protein in Alzheimer disease undergoes fast anterograde axonal transport. Proc Natl Acad Sci USA 1990, 87(4):1561-5.

92. Yamazaki T, Selkoe DJ, Koo EH: Trafficking of cell surface beta-amyloid precursor protein: retrograde and transcytotic transport in cultured neurons. J Cell Biol 1995, 129(2):431-42.

93. Lyckman AW, et al: Post-translational processing and turnover kinetics of presynaptically targeted amyloid precursor superfamily proteins in the central nervous system. J Biol Chem 1998, 273(18):11100-6.
94. Moya $\mathrm{KL}$, et al: The amyloid precursor protein is developmentally regulated and correlated with synaptogenesis. Dev Biol 1994, 161(2):597-603.

95. Hung AY, et al: Increased expression of beta-amyloid precursor protein during neuronal differentiation is not accompanied by secretory cleavage. Proc Natl Acad Sci USA 1992, 89(20):9439-43.

96. Bibel $\mathrm{M}$, et al: Differentiation of mouse embryonic stem cells into a defined neuronal lineage. Nat Neurosci 2004, 7(9):1003-9.

97. Murakami $\mathrm{N}$, et al: Experimental brain injury induces expression of amyloid precursor protein, which may be related to neuronal loss in the hippocampus. J Neurotrauma 1998, 15(11):993-1003.

98. Van den Heuvel C, et al: Upregulation of amyloid precursor protein messenger RNA in response to traumatic brain injury: an ovine head impact model. Exp Neurol 1999, 159(2):441-50.

99. Leyssen $M$, et al: Amyloid precursor protein promotes postdevelopmental neurite arborization in the Drosophila brain. Embo J 2005, 24(16):2944-55, Epub 2005 Jul 28.

100. Rossjohn J, et al: Crystal structure of the N-terminal, growth factor-like domain of Alzheimer amyloid precursor protein. Nat Struct Biol 1999, 6(4):327-31.

101. Saitoh T, et al: Secreted form of amyloid beta protein precursor is involved in the growth regulation of fibroblasts. Cell 1989, 58(4):615-22.

102. Ninomiya $\mathrm{H}$, et al: Amino acid sequence RERMS represents the active domain of amyloid beta/A4 protein precursor that promotes fibroblast growth. J Cell Biol 1993, 121(4):879-86.

103. Meziane $\mathrm{H}$, et al: Memory-enhancing effects of secreted forms of the beta-amyloid precursor protein in normal and amnestic mice. Proc Natl Acad Sci USA 1998, 95(21):12683-8.

104. Roch JM, et al: Increase of synaptic density and memory retention by a peptide representing the trophic domain of the amyloid beta/A4 protein precursor. Proc Natl Acad Sci USA 1994, 91(16):7450-4.

105. Thornton E, et al: Soluble amyloid precursor protein alpha reduces neuronal injury and improves functional outcome following diffuse traumatic brain injury in rats. Brain Res 2006, 1094(1):38-46.

106. Copanaki $E$, et al: sAPPalpha antagonizes dendritic degeneration and neuron death triggered by proteasomal stress. Mol Cell Neurosci 2010, 44(4):386-93.

107. Allinquant $B$, et al: Downregulation of amyloid precursor protein inhibits neurite outgrowth in vitro. J Cell Biol 1995, 128(5):919-27.

108. Perez RG, et al: The beta-amyloid precursor protein of Alzheimer's disease enhances neuron viability and modulates neuronal polarity. J Neurosci 1997, 17(24):9407-14.

109. Herard AS, et al: siRNA targeted against amyloid precursor protein impairs synaptic activity in vivo. Neurobiol Aging 2006, 27(12):1740-50.

110. Taylor CJ, et al: Endogenous secreted amyloid precursor protein-alpha regulates hippocampal NMDA receptor function, long-term potentiation and spatial memory. Neurobiol Dis 2008, 31(2):250-60.

111. Han P, et al: Suppression of cyclin-dependent kinase 5 activation by amyloid precursor protein: a novel excitoprotective mechanism involving modulation of tau phosphorylation. J Neurosci 2005, 25(50):11542-52

112. Caille I, et al: Soluble form of amyloid precursor protein regulates proliferation of progenitors in the adult subventricular zone. Development 2004, 131(9):2173-81, Epub 2004 Apr 8

113. Gakhar-Koppole N, et al: Activity requires soluble amyloid precursor protein alpha to promote neurite outgrowth in neural stem cell-derived neurons via activation of the MAPK pathway. Eur J Neurosci 2008, 28(5):871-82

114. Bergmans BA, et al: Neurons generated from APP/APLP1/APLP2 triple knockout embryonic stem cells behave normally in vitro and in vivo: lack of evidence for a cell autonomous role of the amyloid precursor protein in neuronal differentiation. Stem Cells 2010, 28(3):399-406.

115. Naumann $N$, et al: Transgenic expression of human wild-type amyloid precursor protein decreases neurogenesis in the adult hippocampus. Hippocampus 20(8):971-9.

116. Li H, et al: Soluble amyloid precursor protein (APP) regulates transthyretin and Klotho gene expression without rescuing the essential function of APP. Proc Natl Acad Sci USA 107(40):17362-7.

117. Schwarzman AL, et al: Transthyretin sequesters amyloid beta protein and prevents amyloid formation. Proc Natl Acad Sci USA 1994, 91(18):8368-72. 
118. Choi SH, et al: Accelerated Abeta deposition in APPswe/PS1deltaE9 mice with hemizygous deletions of TTR (transthyretin). Journal of Neuroscience 2007, 27(26):7006-10.

119. Buxbaum JN, et al: Transthyretin protects Alzheimer's mice from the behavioral and biochemical effects of Abeta toxicity. Proceedings of the National Academy of Sciences of the United States of America 2008, 105(7):2681-6.

120. Kuro-o M, et al: Mutation of the mouse klotho gene leads to a syndrome resembling ageing.[see comment]. Nature 1997, 390(6655):45-51.

121. Kurosu $H$, et al: Suppression of aging in mice by the hormone Klotho. Science 2005, 309(5742):1829-33.

122. Imura $A$, et al: alpha-Klotho as a regulator of calcium homeostasis. Science 2007, 316(5831):1615-8.

123. Lannfelt $L$, et al: Amyloid beta-peptide in cerebrospinal fluid in individuals with the Swedish Alzheimer amyloid precursor protein mutation. Neurosci Lett 1995, 199(3):203-6.

124. Sennvik K, et al: Levels of alpha- and beta-secretase cleaved amyloid precursor protein in the cerebrospinal fluid of Alzheimer's disease patients. Neurosci Lett 2000, 278(3):169-72.

125. Colciaghi $F$, et al: [alpha]-Secretase ADAM10 as well as [alpha]APPs is reduced in platelets and CSF of Alzheimer disease patients. Mol Med 2002, 8(2):67-74

126. Tyler SJ, et al: alpha- and beta-secretase: profound changes in Alzheimer's disease. Biochem Biophys Res Commun 2002, 299(3):373-6.

127. Roe CM, et al: Cancer linked to Alzheimer disease but not vascular dementia. Neurology 74(2):106-12.

128. Venkataramani $V$, et al: Histone deacetylase inhibitor valproic acid inhibits cancer cell proliferation via down-regulation of the alzheimer amyloid precursor protein. J Biol Chem 285(14):10678-89.

129. Turner PR, et al: Roles of amyloid precursor protein and its fragments in regulating neural activity, plasticity and memory. Prog Neurobiol 2003, 70(1):1-32

130. Nikolaev A, McLaughlin T, O'Leary DDM, Tessier-Lavigne M: APP binds DR6 to trigger axon pruning and neuron death via distinct caspases. Nature 2009, 457:981-990.

131. Suzuki T, Nakaya T: Regulation of amyloid beta-protein precursor by phosphorylation and protein interactions. J Biol Chem 2008, 283(44):29633-7.

132. lijima K, et al: Neuron-specific phosphorylation of Alzheimer's betaamyloid precursor protein by cyclin-dependent kinase 5 . J Neurochem 2000, 75(3):1085-91.

133. Kimberly WT, et al: Physiological regulation of the beta-amyloid precursor protein signaling domain by c-Jun N-terminal kinase JNK3 during neuronal differentiation. J Neurosci 2005, 25(23):5533-43.

134. Muresan Z, Muresan V: c-Jun NH2-terminal kinase-interacting protein-3 facilitates phosphorylation and controls localization of amyloid-beta precursor protein. J Neurosci 2005, 25(15):3741-51.

135. Scheinfeld $\mathrm{MH}$, et al: Amyloid beta protein precursor is phosphorylated by JNK-1 independent of, yet facilitated by, JNK-interacting protein (JIP)1. J Biol Chem 2003, 278(43):42058-63.

136. Ando $K$, et al: Role of phosphorylation of Alzheimer's amyloid precursor protein during neuronal differentiation. J Neurosci 1999, 19(11):4421-7.

137. Muresan Z, Muresan V: Coordinated transport of phosphorylated amyloidbeta precursor protein and c-Jun $\mathrm{NH} 2$-terminal kinase-interacting protein-1. J Cell Biol 2005, 171(4):615-25.

138. Lee MS, et al: APP processing is regulated by cytoplasmic phosphorylation. J Cell Biol 2003, 163(1):83-95

139. Ando $\mathrm{K}$, et al: Phosphorylation-dependent regulation of the interaction of amyloid precursor protein with Fe65 affects the production of betaamyloid. J Biol Chem 2001, 276(43):40353-61.

140. Tamayev R, Zhou D, D'Adamio L: The interactome of the amyloid beta precursor protein family members is shaped by phosphorylation of their intracellular domains. Mol Neurodegener 2009, 4:28.

141. Taru H, Suzuki T: Facilitation of stress-induced phosphorylation of betaamyloid precursor protein family members by X11-like/Mint2 protein. J Biol Chem 2004, 279(20):21628-36.

142. Pastorino $L$, et al: The prolyl isomerase Pin 1 regulates amyloid precursor protein processing and amyloid-beta production. Nature 2006, 440(7083):528-34.

143. Lu PJ, et al: The prolyl isomerase Pin 1 restores the function of Alzheimerassociated phosphorylated tau protein. Nature 1999, 399(6738):784-8.
144. Sano Y, et al: Physiological mouse brain Abeta levels are not related to the phosphorylation state of threonine-668 of Alzheimer's APP. PLoS One 2006, 1:e51.

145. Koo EH: The beta-amyloid precursor protein (APP) and Alzheimer's disease: does the tail wag the dog? Traffic 2002, 3(11):763-70.

146. King GD, Turner SR: Adaptor protein interactions: modulators of amyloid precursor protein metabolism and Alzheimer's disease risk? Exp Neurol 2004, 185(2):208-19.

147. Barbagallo AP, et al: $\operatorname{Tyr}(682)$ in the intracellular domain of APP regulates amyloidogenic APP processing in vivo. PLOS One 5(11): e15503.

148. Pietrzik CU, et al: FE65 constitutes the functional link between the lowdensity lipoprotein receptor-related protein and the amyloid precursor protein. J Neurosci 2004, 24(17):4259-65.

149. Yankner BA, et al: Neurotoxicity of a fragment of the amyloid precursor associated with Alzheimer's disease. Science 1989, 245(4916):417-20.

150. Oster-Granite ML, et al: Age-dependent neuronal and synaptic degeneration in mice transgenic for the $C$ terminus of the amyloid precursor protein. J Neurosci 1996, 16(21):6732-41.

151. Neve RL, et al: Transgenic mice expressing APP-C100 in the brain. Neurobiol Aging 1996, 17(2):191-203.

152. Cupers $P$, et al: The amyloid precursor protein (APP)-cytoplasmic fragment generated by gamma-secretase is rapidly degraded but distributes partially in a nuclear fraction of neurones in culture. J Neurochem 2001, 78(5):1168-78.

153. Kimberly WT, et al: The intracellular domain of the beta-amyloid precursor protein is stabilized by Fe65 and translocates to the nucleus in a notch-like manner. J Biol Chem 2001, 276(43):40288-92.

154. Passer B, et al: Generation of an apoptotic intracellular peptide by gamma-secretase cleavage of Alzheimer's amyloid beta protein precursor. J Alzheimers Dis 2000, 2(3-4):289-301.

155. Kinoshita $A$, et al: The gamma secretase-generated carboxyl-terminal domain of the amyloid precursor protein induces apoptosis via Tip60 in H4 cells. J Biol Chem 2002, 277(32):28530-6.

156. Chang $\mathrm{KA}$, Suh $\mathrm{YH}$ : Possible roles of amyloid intracellular domain of amyloid precursor protein. BMB Rep 43(10):656-63.

157. Gao Y, Pimplikar SW: The gamma-secretase-cleaved C-terminal fragment of amyloid precursor protein mediates signaling to the nucleus. Proc Natl Acad Sci USA 2001, 98(26):14979-84

158. Ryan KA, Pimplikar SW: Activation of GSK-3 and phosphorylation of CRMP2 in transgenic mice expressing APP intracellular domain. J Cell Biol 2005, 171(2):327-35, Epub 2005 Oct 17.

159. Giliberto L, et al: Transgenic Expression of the Amyloid-beta Precursor Protein-Intracellular Domain Does Not Induce Alzheimer's Disease-Like Traits In Vivo. PLoS One 5(7):e11609.

160. Ghosal K, et al: Alzheimer's disease-like pathological features in transgenic mice expressing the APP intracellular domain. Proc Natl Acad Sci USA 2009, 106(43):18367-72.

161. Lu DC, et al: A second cytotoxic proteolytic peptide derived from amyloid beta-protein precursor. Nat Med 2000, 6(4):397-404

162. Bertrand E, et al: A short cytoplasmic domain of the amyloid precursor protein induces apoptosis in vitro and in vivo. Mol Cell Neurosci 2001, 18(5):503-11.

163. Galvan V, et al: Reversal of Alzheimer's-like pathology and behavior in human APP transgenic mice by mutation of Asp664. Proc Natl Acad Sci USA 2006, 103(18):7130-5, Epub 2006 Apr 25

164. Saganich MJ, et al: Deficits in synaptic transmission and learning in amyloid precursor protein (APP) transgenic mice require C-terminal cleavage of APP. J Neurosci 2006, 26(52):13428-36

165. Park SA, et al: Mechanism of cytotoxicity mediated by the C31 fragment of the amyloid precursor protein. Biochem Biophys Res Commun 2009, 388(2):450-5

166. Harris JA, et al: Many neuronal and behavioral impairments in transgenic mouse models of Alzheimer's disease are independent of caspase cleavage of the amyloid precursor protein. J Neurosci 30(1):372-81.

167. Bredesen DE, John V, Galvan V: Importance of the caspase cleavage site in amyloid-beta protein precursor. J Alzheimers Dis 22(1):57-63.

168. De Strooper B, Annaert W: Novel research horizons for presenilins and gamma-secretases in cell biology and disease. Annu Rev Cell Dev Biol 26:235-60. 
169. Goodger ZV, et al: Nuclear signaling by the APP intracellular domain occurs predominantly through the amyloidogenic processing pathway. J Cell Sci 2009, 122(Pt 20):3703-14.

170. Sala Frigerio $C$, et al: beta-Secretase cleavage is not required for generation of the intracellular C-terminal domain of the amyloid precursor family of proteins. FEBS J 277(6):1503-18.

171. Cao X, Sudhof TC: A transcriptionally [correction of transcriptively] active complex of APP with Fe65 and histone acetyltransferase Tip60. Science 2001, 293(5527):115-20.

172. Scheinfeld MH, Matsuda S, D'Adamio L: JNK-interacting protein-1 promotes transcription of $A$ beta protein precursor but not $A$ beta precursor-like proteins, mechanistically different than Fe65. Proc Natl Acad Sci USA 2003, 100(4):1729-34.

173. Cao $X$, Sudhof TC: Dissection of amyloid-beta precursor proteindependent transcriptional transactivation. J Biol Chem 2004, 279(23):24601-11, Epub 2004 Mar 24

174. Hass MR, Yankner BA: A \{gamma\}-secretase-independent mechanism of signal transduction by the amyloid precursor protein. J Biol Chem 2005, 280(44):36895-904, Epub 2005 Aug 15.

175. Yang $Z$, et al: $A$ dominant role for FE65 (APBB1) in nuclear signaling. J Biol Chem 2006, 281(7):4207-14, Epub 2005 Dec 6.

176. Giliberto L, et al: Evidence that the Amyloid beta Precursor Proteinintracellular domain lowers the stress threshold of neurons and has a "regulated" transcriptional role. Mol Neurodegener 2008, 3:12.

177. Baek SH, et al: Exchange of N-CoR corepressor and Tip60 coactivator complexes links gene expression by NF-kappaB and beta-amyloid precursor protein. Cell 2002, 110(1):55-67.

178. Kim HS, et al: C-terminal fragments of amyloid precursor protein exert neurotoxicity by inducing glycogen synthase kinase-3beta expression. FASEB J 2003, 17(13):1951-3.

179. Pardossi-Piquard $R$, et al: Presenilin-dependent transcriptional control of the Abeta-degrading enzyme neprilysin by intracellular domains of betaAPP and APLP. Neuron 2005, 46(4):541-54.

180. Zhang YW, et al: Presenilin/gamma-secretase-dependent processing of beta-amyloid precursor protein regulates EGF receptor expression. Proc Natl Acad Sci USA 2007, 104(25):10613-8, Epub 2007 Jun 7

181. Checler F, et al: The gamma/epsilon-secretase-derived APP intracellular domain fragments regulate p53. Current Alzheimer Research 2007, 4(4):423-6.

182. Liu Q, et al: Amyloid Precursor Protein Regulates Brain Apolipoprotein E and Cholesterol Metabolism through Lipoprotein Receptor LRP1. Neuron 2007, 56(1):66-78.

183. von Rotz RC, et al: The APP intracellular domain forms nuclear multiprotein complexes and regulates the transcription of its own precursor. J Cell Sci 2004, 117(Pt 19):4435-48.

184. Leissring $M A$, et al: A physiologic signaling role for the gamma-secretasederived intracellular fragment of APP. Proc Natl Acad Sci USA 2002, 99(7):4697-702.

185. Muller T, et al: Modulation of gene expression and cytoskeletal dynamics by the amyloid precursor protein intracellular domain (AICD). Mol Biol Cell 2007, 18(1):201-10.

186. Hebert SS, et al: Regulated intramembrane proteolysis of amyloid precursor protein and regulation of expression of putative target genes. EMBO Rep 2006, 7(7):739-45, Epub 2006 May 19.

187. Chen AC, Selkoe DJ: Response to: Pardossi-Piquard et al., "PresenilinDependent Transcriptional Control of the Abeta-Degrading Enzyme Neprilysin by Intracellular Domains of betaAPP and APLP." Neuron 46, 541-554. Neuron 2007, 53(4):479-83.

188. Repetto E, et al: Presenilin 1 regulates epidermal growth factor receptor turnover and signaling in the endosomal-lysosomal pathway. Journal of Biological Chemistry 2007, 282(43):31504-16.

189. Tamboli IY, et al: Loss of gamma-secretase function impairs endocytosis of lipoprotein particles and membrane cholesterol homeostasis. J Neurosci 2008, 28(46):12097-106.

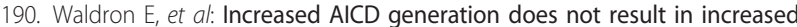
nuclear translocation or activation of target gene transcription. Exp Cell Res 2008, 314(13):2419-33.

191. Hornsten A, et al: APL-1, a Caenorhabditis elegans protein related to the human beta-amyloid precursor protein, is essential for viability. Proc Natl Acad Sci USA 2007, 104(6):1971-6, Epub 2007 Jan 31.
192. Wiese M, Antebi A, Zheng H: Intracellular trafficking and synaptic function of APL-1 in Caenorhabditis elegans. PLOS One 5(9)

193. Li H, et al: Genetic dissection of the amyloid precursor protein in developmental function and amyloid pathogenesis. $J \mathrm{Biol}$ Chem 285(40):30598-605.

194. Gunawardena S, Goldstein LS: Disruption of axonal transport and neuronal viability by amyloid precursor protein mutations in Drosophila. Neuron 2001, 32(3):389-401

195. Torroja $L$, et al: Neuronal overexpression of APPL, the Drosophila homologue of the amyloid precursor protein (APP), disrupts axonal transport. Curr Biol 1999, 9(9):489-92.

196. Kamal A, et al: Kinesin-mediated axonal transport of a membrane compartment containing beta-secretase and presenilin-1 requires APP. Nature 2001, 414(6864):643-8.

197. Satpute-Krishnan P, DeGiorgis JA, Bearer EL: Fast anterograde transport of herpes simplex virus: role for the amyloid precursor protein of alzheimer's disease. Aging Cell 2003, 2(6):305-18.

198. Satpute-Krishnan $P$, et al: A peptide zipcode sufficient for anterograde transport within amyloid precursor protein. Proc Natl Acad Sci USA 2006 103(44):16532-7, Epub 2006 Oct 24.

199. Lazarov O, et al: Axonal transport, amyloid precursor protein, kinesin-1, and the processing apparatus: revisited. J Neurosci 2005, 25(9):2386-95.

200. Torroja L, Luo L, White K: APPL, the Drosophila member of the APPfamily, exhibits differential trafficking and processing in CNS neurons. J Neurosci 1996, 16(15):4638-50.

201. Ashley J, et al: Fasciclin II signals new synapse formation through amyloid precursor protein and the scaffolding protein $\mathrm{dX} 11 /$ Mint. J Neurosci 2005, 25(25):5943-55.

202. Fossgreen A, et al: Transgenic Drosophila expressing human amyloid precursor protein show gamma-secretase activity and a blistered-wing phenotype. Proc Natl Acad Sci USA 1998, 95(23):13703-8.

203. Merdes G, et al: Interference of human and Drosophila APP and APP-like proteins with PNS development in Drosophila. Embo J 2004, 23(20):4082-95.

204. Muller $U$, et al: Behavioral and anatomical deficits in mice homozygous for a modified beta-amyloid precursor protein gene. Cell 1994, 79(5):755-65.

205. Zheng $H$, et al: beta-Amyloid precursor protein-deficient mice show reactive gliosis and decreased locomotor activity. Cell 1995, 81(4):525-31.

206. Li ZW, et al: Generation of mice with a 200-kb amyloid precursor protein gene deletion by Cre recombinase-mediated site-specific recombination in embryonic stem cells. Proc Natl Acad Sci USA 1996, 93(12):6158-62.

207. Ring S, et al: The secreted beta-amyloid precursor protein ectodomain APPs alpha is sufficient to rescue the anatomical, behavioral, and electrophysiological abnormalities of APP-deficient mice. J Neurosci 2007, 27(29):7817-26.

208. Magara F, et al: Genetic background changes the pattern of forebrain commissure defects in transgenic mice underexpressing the betaamyloid-precursor protein. Proc Natl Acad Sci USA 1999, 96(8):4656-61.

209. Steinbach JP, et al: Hypersensitivity to seizures in beta-amyloid precursor protein deficient mice. Cell Death Differ 1998, 5(10):858-66.

210. Phinney $A L$, et al: No hippocampal neuron or synaptic bouton loss in learning-impaired aged beta-amyloid precursor protein-null mice. Neuroscience 1999, 90(4):1207-16.

211. Priller $C$, et al: Synapse formation and function is modulated by the amyloid precursor protein. J Neurosci 2006, 26(27):7212-21.

212. Bittner $T$, et al: Gamma-secretase inhibition reduces spine density in vivo via an amyloid precursor protein-dependent pathway. J Neurosci 2009, 29(33):10405-9.

213. Lee $\mathrm{KJ}$, et al: Beta amyloid-independent role of amyloid precursor protein in generation and maintenance of dendritic spines. Neuroscience 169(1):344-56.

214. Dawson GR, et al: Age-related cognitive deficits, impaired long-term potentiation and reduction in synaptic marker density in mice lacking the beta-amyloid precursor protein. Neuroscience 1999, 90(1):1-13.

215. Seabrook $G R$, et al: Mechanisms contributing to the deficits in hippocampal synaptic plasticity in mice lacking amyloid precursor protein. Neuropharmacology 1999, 38(3):349-59.

216. Yang $L$, et al: Amyloid precursor protein regulates Cav1.2 L-type calcium channel levels and function to influence GABAergic short-term plasticity. J Neurosci 2009, 29(50):15660-8. 
217. Santos SF, et al: Expression of human amyloid precursor protein in rat cortical neurons inhibits calcium oscillations. J Neurosci 2009, 29(15):4708-18.

218. Yang $L$, et al: Increased asynchronous release and aberrant calcium channel activation in amyloid precursor protein deficient neuromuscular synapses. Neuroscience 2007, 149(4):768-78, Epub 2007 Aug 28.

219. von Koch CS, et al: Generation of APLP2 KO mice and early postnatal lethality in APLP2/APP double KO mice. Neurobiol Aging 1997, 18(6):661-9.

220. Heber S, et al: Mice with combined gene knock-outs reveal essential and partially redundant functions of amyloid precursor protein family members. J Neurosci 2000, 20(21):7951-63.

221. Wang $P$, et al: Defective neuromuscular synapses in mice lacking amyloid precursor protein (APP) and APP-Like protein 2. J Neurosci 2005, 25(5):1219-25.

222. Yang $G$, et al: Reduced synaptic vesicle density and active zone size in mice lacking amyloid precursor protein (APP) and APP-like protein 2. Neurosci Lett 2005, 384(1-2):66-71.

223. Wang B, et al: Amyolid precursor protein mediates presynaptic localization and activity of the high-affinity choline transporter. Proc Natl Acad Sci USA 2007, 104:14140-14145.

224. Herms J, et al: Cortical dysplasia resembling human type 2 lissencephaly in mice lacking all three APP family members. Embo J 2004, 23(20):4106-15.

225. Guenette $\mathrm{S}$, et al: Essential roles for the FE65 amyloid precursor proteininteracting proteins in brain development. Embo J 2006, 25(2):420-31 Epub 2006 Jan 12.

226. Lambert de Rouvroit C, Goffinet AM: Neuronal migration. Mech Dev 2001, 105(1-2):47-56.

227. Ring $S$, et al: The secreted beta-amyloid precursor protein ectodomain APPs alpha is sufficient to rescue the anatomical, behavioral, and electrophysiological abnormalities of APP-deficient mice. J Neurosci 2007, 27(29):7817-26.

228. Barbagallo AP, et al: A single tyrosine residue in the amyloid precursor protein intracellular domain is essential for developmental function. J Biol Chem .

\section{Submit your next manuscript to BioMed Central and take full advantage of:}

- Convenient online submission

- Thorough peer review

- No space constraints or color figure charges

- Immediate publication on acceptance

- Inclusion in PubMed, CAS, Scopus and Google Scholar

- Research which is freely available for redistribution 